\title{
Hydrogel-filled micropipette contact systems for solid state electrochemical measurements
}

\author{
Margherita Donnici ${ }^{1} \cdot$ Salvatore Daniele ${ }^{1}$ (i) \\ Received: 30 April 2020 / Revised: 11 May 2020 / Accepted: 11 May 2020 / Published online: 18 May 2020 \\ (C) Springer-Verlag GmbH Germany, part of Springer Nature 2020
}

\begin{abstract}
This paper reports on the use of a novel microcapillary system for solid contact electrochemical measurements. The probe is made of moveable micropipettes, with orifice of 1-30- $\mu$ m radii, filled with a conducting hydrogel, which forms a thin-gelled meniscus at the pipette end. The hydrogel is made of $2 \%(\mathrm{w} / \mathrm{v})$ agarose and water solutions, containing $\mathrm{KCl}$ or $\mathrm{KNO}_{3}$ as supporting electrolytes. The micropipette can be brought in contact with a conducting substrate to form a microcell, which allows performing voltammetric measurements confined within limited contact regions. The suitability of the proposed probe for local electrochemical measurements are tested using two electroactive species, dissolved in the hydrogel, namely $\left[\mathrm{Fe}\left(\mathrm{CN}_{6}\right)\right]^{4-} \mathrm{and} \mathrm{Ag}^{+}$ions. Mass transport characteristics of the two species, in bulk hydrogel and at micropipette meniscuses of different radii, are examined in detail in the frame of existing theory. For comparison, voltammetric measurements are also performed with micropipettes filled with the corresponding aqueous solutions. It is shown that the gel-filled micropipette, at variance with the aqueous one, prevents the spreading and leakage of solution on the sample surface. The microprobe developed here can be useful to perform electrochemical measurements on surfaces, which suffer from direct contact with liquid electrolytes. A proof-of-concept hydrogelcapillary measurement is performed to distinguish the presence of metallic silver deposited on a graphite-on-paper-based material, realized through simple pencil strokes.
\end{abstract}

Keywords Microcapillary $\cdot$ Agarose $\cdot$ Hydrogel $\cdot$ Voltammetry $\cdot$ Silver deposits $\cdot$ Graphite-on-paper

\section{Introduction}

Polymeric gels (PGs) prepared by biopolymers (BPs), such as starch, pectin, or agar, have been extensively used in different areas including biology [1] and food industry [2,3]. PGs have also been frequently used in electrochemical devices such as batteries, accumulators [4, 5], solar cells [6], and sensors [7]. In the latter field, biopolymeric gels (BPGs) have been used to avoid adverse effects arising from organic matter, which can adsorb onto the electrode surface [8], to minimize contribution due to natural convection in the mass transport [9], and to accommodate nanomaterials within its matrix for sensor

Electronic supplementary material The online version of this article (https://doi.org/10.1007/s10008-020-04651-w) contains supplementary material, which is available to authorized users.

Salvatore Daniele

sig@unive.it

1 Department of Molecular Sciences and Nanosystems, Ca' Foscari University of Venice, Via Torino 155, 30137 Venice, Italy applications [7]. Recently, BPGs have found applications to construct contact electrochemical cells for solid surface analysis by using electrochemical impedance spectroscopy [10-14]. These systems were employed for studying corrosion processes and characterize in situ large surface areas (i.e., over $\mathrm{cm}^{2}$ sizes) of patinas and protective coatings of cultural heritage materials. Miniaturized hydrogel-integrated systems for studying localized electrochemical events by voltammetry or potentiometry have also been reported. In $[15,16]$, a layer of chitosan has been electrodeposited on microdisk electrodes, and the gel has been loaded with suitable redox species to perform voltammetric [15] or potentiometric [16] measurements. In [17] a pyramid-shaped tip, composed of agarose, has been fabricated from a master prepared by conventional photolithography and subsequent anisotropic etching. The hydrogel tip has been then filled with an electrolyte through an equilibrium process by soaking the gel-pyramid in the electrolyte solution. These probes, combined with a scanning system, other than probing the surface reactivity, have allowed to image the topography of the substrate or to fabricate, by electrodeposition, 3D nanostructures. 
In this work, we propose, for the first time, an alternative gel-integrated electrochemical microprobe for contact electrochemical measurements, exploiting the principle of the microcapillary-based technique [18-25]. The system proposed here employs a micropipette (Fig. 1a), which is filled with an ionically conductive hydrogel. The latter is made of a polysaccharide and an aqueous solution containing an electrolyte. A thin layer of hydrogel, protruding from the micropipette end, is formed. A two-electrode microelectrochemical cell can be formed by a pseudoreference/counter electrode (usually a Pt or Ag wire), immersed in the hydrogel medium within the micropipette, and a working electrode made by the small portion of a conducting substrate that comes into contact with the gelled meniscus (Fig. 1b). Agarose has been chosen as polysaccharide because it provides an uncharged matrix thus miming molecular solvents, in which free diffusion of the electroactive species can occur, regardless of whether they are charged or not [26]. In addition, the agarose hydrogel brings the advantage of being cheap, biodegradable, nontoxic, and can be easily prepared. The system proposed here can be useful to make electrochemical measurements on surfaces of materials which suffer from direct contact with liquid electrolytes. The voltammetric characteristics of the hydrogel containing either the soluble redox probes $\left[\mathrm{Ru}\left(\mathrm{NH}_{3}\right)_{6}\right]^{3+}$ and $\left[\mathrm{Fe}(\mathrm{CN})_{6}\right]^{4-}$ or $\mathrm{Ag}^{+}$ ions, whose reduction provides metallic silver, are firstly investigated in the bulk medium by using a platinum microdisk electrode to obtain mass transport parameters. The suitability of the gelled microprobe for voltammetric contact measurements is then explored by using gold and platinum substrates. For comparison, voltammetric measurements are performed in the corresponding aqueous solutions, using either the platinum microdisk or the micropipette. Proof-of-concept measurements are also presented to characterize micro areas of metallic silver deposited on to the surface of a pencil graphite line deposited on a paper material.

\section{Experimental}

\section{Chemicals}

Potassium ferrocyanide, potassium chloride, potassium nitrate, silver nitrate (standard solution $0.1 \mathrm{M}$ ), hexaammineruthenium(III) trichloride, agarose powder (99\%), disodium carbonate, and formaldehyde were purchased from Sigma Aldrich and used as received. All aqueous solutions were prepared with deionized water purified via a Milli-Q unit (Millipore system). When required, pure nitrogen (99.99\%, from SIAD, Italy) was used to deaerate the aqueous solutions.

\section{Hydrogel preparation}

A weighted amount of agarose powder was added in Milli-Q water at room temperature to provide a series of $2 \% \mathrm{w} / \mathrm{v}$ suspensions. The appropriate amounts of the redox probes and $\mathrm{KCl}$ or $\mathrm{KNO}_{3}$, as supporting electrolyte, were then added to obtain the desired hydrogel compositions. The mixtures were slowly heated up to $80^{\circ} \mathrm{C}$ in sealed containers to avoid water evaporation. During the heating, the suspensions were gently stirred to avoid the formation of gas bubbles. The mixtures were kept at $80{ }^{\circ} \mathrm{C}$ until they displayed a clear appearance (Fig. S1), and afterwards, cooled down at room temperature.

\section{Micropipette fabrication}

Tapered micropipettes were fabricated by pulling borosilicate capillaries of dimensions 1.0 (o.d.), $0.58 \mathrm{~mm}$ (i.d.) (Sutter) using a laser puller (P-2000, Sutter Instruments, USA) with the following parameters: heat $=320$, filament $=2$, velocity $=$ 15 , delay $=128$, and pull $=100$. Subsequently, the obtained micropipettes were polished flat to reveal openings, whose sizes, as estimated by SEM, varied between 2- and $80-\mu \mathrm{m}$ diameters. The micropipettes were filled with either the ionic
Fig. 1 Schematic of the experimental setup using a hydrogel-filled micropipette. a Micropipette approaching the substrate while it is in air; $\mathbf{b}$ gelled meniscus landed on the substrate that forms the electrochemical cell
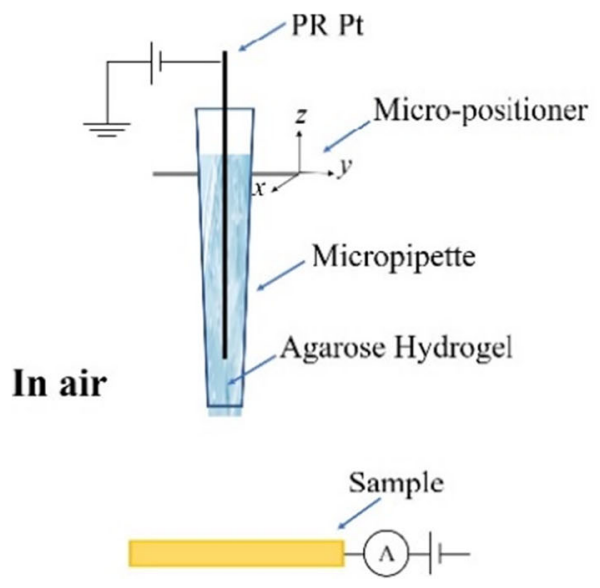

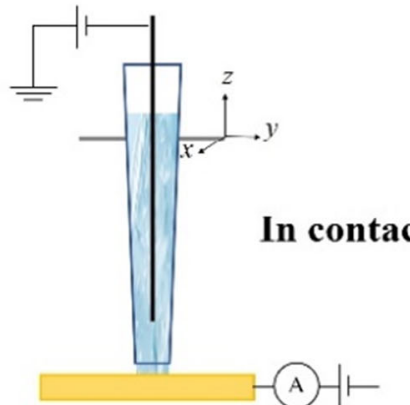


hydrogel or aqueous solutions by capillarity. Contrary to the normal practice $[27,28]$, the outer walls of the microcapillaries were not silanized.

\section{Preparation of silver deposits on graphite-on-paper- based material}

A pencil-drawn paper support material [29] was prepared by hand drawing a $20-\mathrm{mm}$ long $\times 6$ - $\mathrm{mm}$ wide line on a piece of Whatman no. 1 paper sheet using a Bic \#2 graphite pencil. Fifty microliters of an $\mathrm{AgNO}_{3} 0.1 \mathrm{M}$ aqueous solution were cast on the graphite layer, and the solvent was allowed to evaporate overnight in a controlled environment, avoiding exposure to light. Afterward, the spot was treated with a 1:1 (v/v) $\mathrm{Na}_{2} \mathrm{CO}_{3}\left(5 \mathrm{~g}\right.$ in $\left.100 \mathrm{~mL} \mathrm{H} \mathrm{H}_{2} \mathrm{O}\right)$ and formaldehyde (37\% $\mathrm{CH}_{2} \mathrm{O}, 5 \mathrm{~mL}$ in $100 \mathrm{~mL} \mathrm{H}_{2} \mathrm{O}$ ) solution to allow the reduction of silver ions [30]. The excess of the reagents was eliminated by rinsing the sample with milli-Q water. Finally, the spot was dried in the controlled environment.

\section{Instrumentation and electrodes}

All voltammetric experiments were performed in a twoelectrode cell maintained in a Faraday cage made of sheets of aluminium to minimize external noise. In all cases, the cell was arranged in a two-electrode configuration, as outlined below. For bulk solution measurements a platinum microdisk was used as working electrode, while a platinum wire with $380-\mu \mathrm{m}$ diameter was employed as pseudoreference (PRPt)/ counter electrode. The Pt microelectrode was prepared by sealing a platinum wire (Goodfellow Metals, Cambridge, UK) of $25-\mu \mathrm{m}$ nominal diameter in glassy capillaries, following a standard procedure [30]. The geometric radius of the microdisk was calibrated by recording the steady-state diffusion limiting current $\left(I_{\mathrm{ss}}\right)$ from a $1 \mathrm{mM} \mathrm{Ru}\left(\mathrm{NH}_{3}\right)_{6} \mathrm{Cl}_{3}$ solutioncontaining $0.1 \mathrm{M} \mathrm{KCl}$, and using the following equation [31]:

$I_{\mathrm{ss}}=4 n F D c^{\mathrm{b}} a$

where $n$ is the number of electrons, $F$ is the Faraday constant, $D$ is the diffusion coefficient of the electroactive species (in this case $\left.7.0 \times 10^{-6} \mathrm{~cm}^{2} \mathrm{~s}^{-1}[32]\right), c^{\mathrm{b}}$ is the bulk concentration, and $a$ is the radius of the microdisk.

For the measurements with the micropipettes, the confined electrochemical cell (made by the PRPt, immersed within the hydrogel or aqueous solutions filling the micropipette, and the working electrode made by the small surface area of a platinum or gold substrate wet by the pipette meniscus) was placed in a sealed chamber (Fig. S2) to maintain adequate levels of humidity to prevent solvent evaporation from the micropipette meniscus. This was also ensured by placing in the chamber a sponge soaked with Milli-Q water. All voltammetric measurements were performed with a CHI920B SECM workstation
(CH instruments); its integrated micropositioning device was used to displace the micropipette above the substrate with high accuracy. Unless otherwise stated, the electrochemical measurements were performed in aerated media at room temperature $\left(22 \pm 1^{\circ} \mathrm{C}\right)$.

\section{Results and Discussion}

\section{Potential windows and open circuit potentials in the bulk of the agarose hydrogels}

Preliminary, cyclic voltammograms (CVs) were recorded in the bulk of the aerated hydrogels to establish the potential windows available at a Pt microdisk electrode. Figure 2 shows typical responses obtained in the hydrogels containing $0.1 \mathrm{M}$ $\mathrm{KNO}_{3}$ (blue line) or $0.1 \mathrm{M} \mathrm{KCl}$ (black line). In the cathodic scan, waves with half-wave potential $\left(E_{1 / 2}\right)$ of $-0.50 \mathrm{~V}$ (in $0.1 \mathrm{M} \mathrm{KCl}$ ) and $-0.60 \mathrm{~V}$ (in $0.1 \mathrm{M} \mathrm{KNO}_{3}$ ) were observed (inset in Fig. 2). These were assigned to the oxygen reduction process, as the solutions were not deaerated. The onsets of the cathodic limits occurred at about $-1.1 \mathrm{~V}$ and $-1.2 \mathrm{~V}$ in the medium containing $\mathrm{KCl}$ and $\mathrm{KNO}_{3}$, respectively. In the anodic scan, a featureless voltammogram up to the onset of the background discharge, taking place at about $1.4 \mathrm{~V}$, was recorded in $0.1 \mathrm{M} \mathrm{KNO}_{3}$. Instead, in $0.1 \mathrm{M} \mathrm{KCl}$, prior the onset of background discharge that occurred also at about $1.4 \mathrm{~V}$, a wave with $E_{1 / 2}$ equal to $1.2 \mathrm{~V}$, conceivably due to the $\mathrm{Cl}^{-}$ oxidation [33], was observed. These results therefore indicate that, within the above limits, no process due to the organic matter present in the medium occurs.

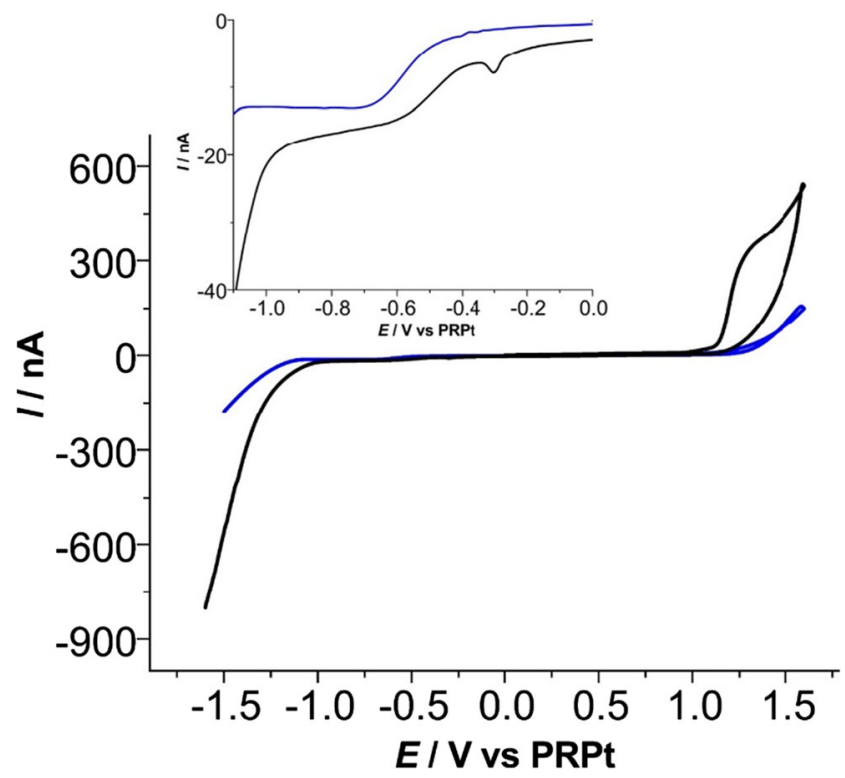

Fig. 2 Cyclic voltammograms recorded at a $\mathrm{Pt} 12.5-\mu \mathrm{m}$ radius in agarose hydrogel containing $0.1 \mathrm{M} \mathrm{KNO}_{3}$ (blue line) and $0.1 \mathrm{M} \mathrm{KCl}$ (black line). Scan rate $100 \mathrm{mV} \mathrm{s}^{-1}$ 
The stability of the ionic hydrogel and the effect of agarose at the electrode/hydrogel interface were also investigated by performing open circuit potential (OCP) measurements. It was observed that stable OCPs were achieved after about 90-100 s and set at $-22( \pm 5) \mathrm{mV}$ and $-80( \pm 15) \mathrm{mV}$ in the $0.1 \mathrm{M} \mathrm{KCl}$ and $0.1 \mathrm{M} \mathrm{KNO}_{3}$ media, respectively. The higher reproducibility observed in the $\mathrm{KCl}$ medium was probably due to the adsorption strength of chloride ions, higher than that of other anions, onto platinum electrode surfaces [34]. This, presumably, provided a more stable Pt/hydrogel interface, which prevented, to some extent, the possible formation of an agarose layer on the electrode surface, due to adsorption phenomena, as often happens to Pt electrodes, in the presence of organic matter [35].

Similar measurements performed in the above media containing also $1 \mathrm{mM}$ of the redox probes produced slight changes in the OPC values, i.e., of about $50 \mathrm{mV}$ and $13 \mathrm{mV}$ towards less negative potentials in the presence of $\mathrm{Ru}\left(\mathrm{NH}_{3}\right)_{6}{ }^{3+}$ and $\mathrm{Fe}(\mathrm{CN})_{6}^{4-}$, respectively.

\section{Voltammetric behavior of soluble redox probes in the bulk of aqueous and agarose hydrogel media}

Preliminarily, mass transport characteristics of the redox probes $\left[\mathrm{Ru}\left(\mathrm{NH}_{3}\right)_{6}\right]^{3+}$ and $\left[\mathrm{Fe}(\mathrm{CN})_{6}\right]^{4-}$ in the $2 \%(\mathrm{w} / \mathrm{v})$ agarose were obtained in the bulk media, using the Pt microelectrode. For comparison, measurements were also performed in the corresponding gel-free aqueous media. These measurements were limited to the hydrogel/ electrode systems containing $0.1 \mathrm{M} \mathrm{KCl}$ as supporting electrolyte, which was employed for microcapillary measurements (see next section).

Figure 3 (full lines) contrasts typical CVs obtained at $5 \mathrm{mV}$ $\mathrm{s}^{-1}$ in $1 \mathrm{mM}$ each of $\left[\mathrm{Ru}\left(\mathrm{NH}_{3}\right)_{6}\right]^{3+}$ (Fig. 3a) and $\left[\mathrm{Fe}(\mathrm{CN})_{6}\right]^{4-}$ (Fig. 3b) aerated aqueous and agarose-gel media. In both cases, sigmoidal waves, typical for microelectrodes working under steady-state conditions, are evident [36]. The lack of a well-defined current plateau for $\mathrm{Ru}\left(\mathrm{NH}_{3}\right)_{6}{ }^{3+}$ was due to the presence of oxygen, whose reduction process, at potential negative to $-0.4 \mathrm{~V}$, partially overlapped with that of the redox probe. This effect was less marked in the agarose hydrogel, probably because of the lower diffusion coefficient of $\mathrm{O}_{2}$ in the gel (i.e., $9.18 \times 10^{-6} \mathrm{~cm}^{2} \mathrm{~s}^{-1}$ ) [37] with respect to water solutions (i.e., $2.12 \times 10^{-5} \mathrm{~cm}^{2} \mathrm{~s}^{-1}$ ) [38]. In fact, in deaerated aqueous media, using the same Pt microelectrode, the reduction of $\mathrm{Ru}\left(\mathrm{NH}_{3}\right)_{6}{ }^{3+}$ provided a better-defined current plateau (see CV with a red dashed line in Fig. 3a).

From the steady state limiting currents, and the use of Eq. (1), diffusion coefficient values for both redox probes were calculated and are shown in Table 1. In the hydrogel, diffusion coefficients $\left(D_{\text {gel }}\right)$ are lower than those in aqueous solution $\left(D_{\text {aq }}\right)$, the $D_{\text {gel }} / D_{\text {aq }}$ ratios being 0.76 and 0.68 for $\left[\mathrm{Ru}\left(\mathrm{NH}_{3}\right)_{6}\right]^{3+}$ and $\left[\mathrm{Fe}(\mathrm{CN})_{6}\right]^{4-}$, respectively. For $\left[\mathrm{Ru}\left(\mathrm{NH}_{3}\right)_{6}\right]^{3+}, D_{\text {gel }} / D_{\text {aq }}$ found
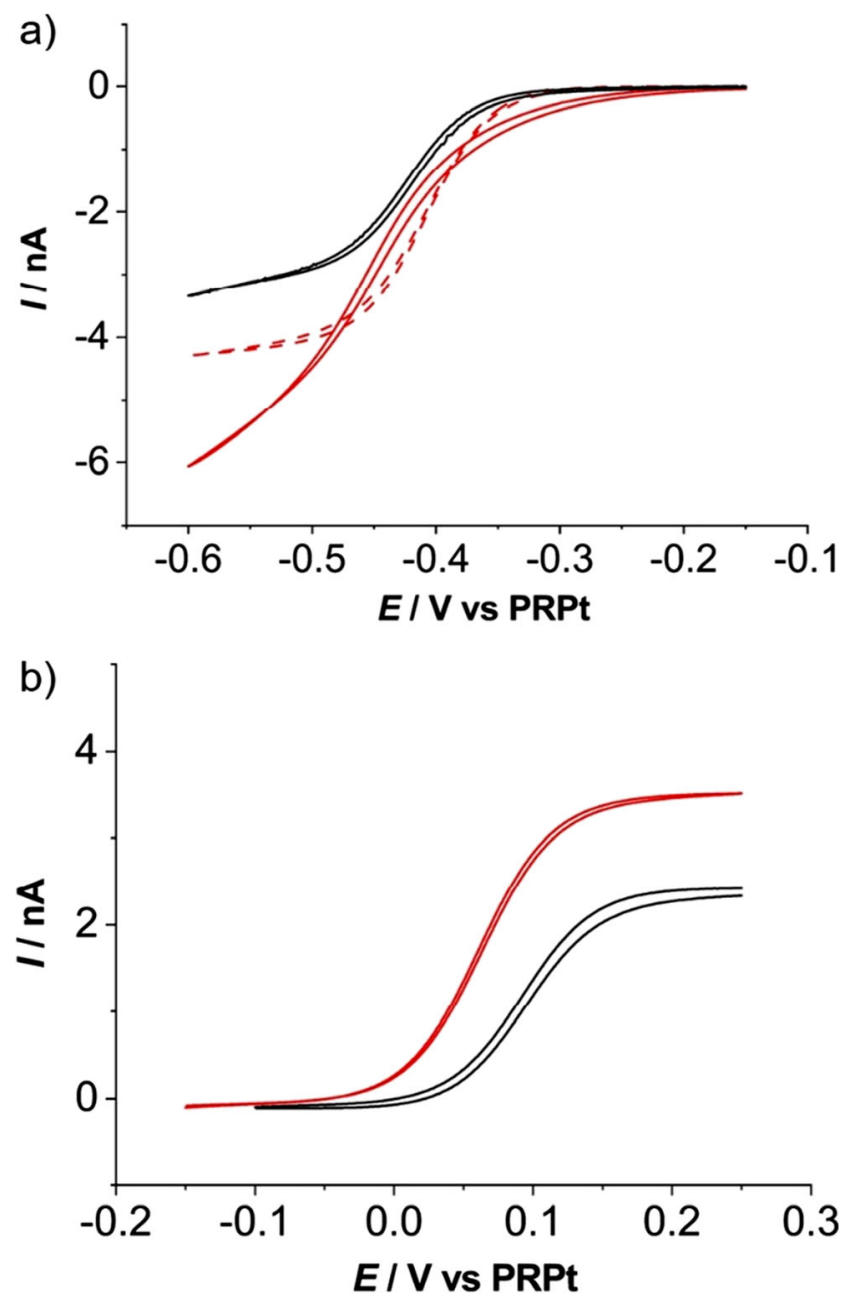

Fig. 3 Cyclic voltammograms recorded at a Pt microdisk $12.5-\mu$ m radius in a $1 \mathrm{mM}\left[\mathrm{Ru}\left(\mathrm{NH}_{3}\right)_{6}\right]^{3+}$ and $\mathbf{b} 1 \mathrm{mM}\left[\mathrm{Fe}(\mathrm{CN})_{6}\right]^{4-}$ solutions. Black and red full lines refer to the aerated agarose hydrogel and aqueous media, respectively; the red dashed line in (a) refers to the de-aerated aqueous solution

here is consistent with 0.80 reported in [39] (where a $0.5 \%$ $(\mathrm{w} / \mathrm{v})$ agarose hydrogel $+0.1 \mathrm{M} \mathrm{KCl}$ medium was investigated), though absolute diffusion coefficient values in both media were larger than those shown in Table 1 (i.e., $D_{\text {gel }}=7.84 \times 10^{-6} \mathrm{~cm}^{2}$ $\mathrm{s}^{-1}$ and $D_{\mathrm{aq}}=9.78 \times 10^{-6} \mathrm{~cm}^{2} \mathrm{~s}^{-1}$ ).

Table 1 Diffusion coefficient values of the redox probes in aqueous solution $\left(D_{\mathrm{aq}}\right)$ and in $2 \%(\mathrm{w} / \mathrm{v})$ agarose hydrogel $\left(D_{\mathrm{gel}}\right)$, both media containing $1 \mathrm{mM}$ of the electroactive specie and $0.1 \mathrm{M} \mathrm{KCl}$

\begin{tabular}{llll}
\hline Redox probe & $D_{\text {aq }}\left(\times 10^{6} \mathrm{~cm}^{2} \mathrm{~s}^{-1}\right)^{*}$ & $D_{\text {gel }}\left(\times 10^{6} \mathrm{~cm}^{2} \mathrm{~s}^{-1}\right)^{*}$ & $D_{\text {gel }} / D_{\text {aq }}$ \\
\hline$\left[\mathrm{Fe}(\mathrm{CN})_{6}\right]^{4-}$ & $6.52( \pm 0.11)$ & $4.43( \pm 0.13)$ & 0.68 \\
{$\left[\mathrm{Ru}\left(\mathrm{NH}_{3}\right)_{6}\right]^{3+}$} & $7.45( \pm 0.14)^{* *}$ & $5.66( \pm 0.14)$ & 0.76 \\
$\mathrm{Ag}^{+}$ & $15.1( \pm 0.2)$ & $11.3( \pm 0.2)$ & 0.75 \\
\hline
\end{tabular}

*Average values from three replicates. **Obtained in deaerate aqueous solution 


\section{Microcapillary voltammetry using the micropipette filled with hydrogel and aqueous solutions}

Microcapillary contact measurements were performed with the micropipettes filled with either the hydrogel or the corresponding agarose-free aqueous solution, containing $1 \mathrm{mM}$ $\left[\mathrm{Fe}(\mathrm{CN})_{6}\right]^{4-}$ and $0.1 \mathrm{M} \mathrm{KCl}$; an Au-coated glass surface was employed as the substrate. The micropipette was mounted on the micropositioning system and moved towards the substrate (Fig. 4a, initially, at $10 \mu \mathrm{m} \mathrm{s}^{-1}$ and subsequently more finely at $0.1 \mu \mathrm{m} \mathrm{s}^{-1}$. The substrate was held at $+0.4 \mathrm{~V}$, and the current flow was monitored continuously. Upon contact of the meniscus at the end of the pipette with the substrate, a current spike was observed (see as an example Fig. 4a), and the approach was automatically stopped. The pipette was held in place and series of CVs were run at different scan rates, over the range $5-75 \mathrm{mV} \mathrm{s}^{-1}$. Typical CVs obtained with the micropipette filled with the hydrogel and the aqueous solutions are shown in Fig. 4 b and c, respectively. It is worth to note that the two series of measurements were performed using the same micropipette having an opening radius of $30 \mu \mathrm{m}$. As evident from Fig. 4b, c, in both media, peak-shaped responses, typical for planar diffusion, were obtained. This is contrary to the features observed above with the microelectrode in the bulk media and is related to the fact that, for the size of the meniscuses involved in these measurements, the current is essentially dominated by the linear diffusion through the capillary. This behavior agrees with previous reports $[30,40]$. The analysis of the forward peak current $\left(I_{\mathrm{p}}\right)$ against the square root of scan rate ( $v)$ (insets in Fig. 4b,c) provided linear trends, congruently with Eq. (2) that holds for planar diffusion [36]:

$$
I_{\mathrm{p}}=2.69 \times 10^{5} n^{3 / 2} A D^{1 / 2} C v^{1 / 2}
$$

where $A$ is the surface area of the substrate wet by the meniscus; other symbols have their usual meanings. Linear regression analysis of the experimental data provided the following relationships: $I_{\mathrm{p}}(\mathrm{nA})=21.2( \pm 0.4) v^{1 / 2}\left(v, \mathrm{~V} \mathrm{~s}^{-1}\right)+0.05( \pm$ $0.02)\left(R^{2}=0.997\right)$ and $I_{\mathrm{p}}(\mathrm{nA})=394( \pm 15) v^{1 / 2}\left(v, \mathrm{~V} \mathrm{~s}^{-1}\right)+$ $1.2( \pm 0.2)\left(R^{2}=0.993\right)$ for the hydrogel- and aqueous-filled micropipette, respectively. Further analysis of the CV responses provided $E_{1 / 2}=0.014( \pm 0.003) \mathrm{V}$ vs. PRPt and a cathodic to anodic peak separation $\left(\Delta E_{\mathrm{p}}\right)$ of $68( \pm 3) \mathrm{mV}$ regardless of scan rate, for the hydrogel-filled micropipette, indicating, essentially, the occurrence of a reversible electrode process. For the pipette filled with the aqueous solution, $E_{1 / 2}=$ $0.045( \pm 0.003) \mathrm{V}$ vs. PRPt and $\Delta E_{\mathrm{p}}$ values varying from 65 to $230 \mathrm{mV}$, upon varying the scan rate from 5 to $75 \mathrm{mV} \mathrm{s}^{-1}$, were instead found. The gradual change in shape of voltammograms (i.e., more drawn-out responses) at higher scan rates could be due to ohmic drop effects [41]. However, considering the relatively small currents involved in the measurements,

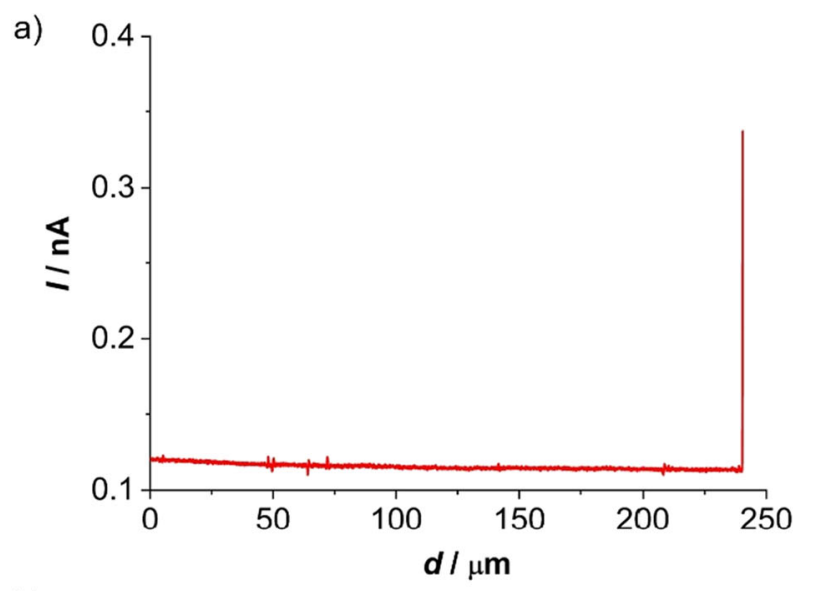

b)

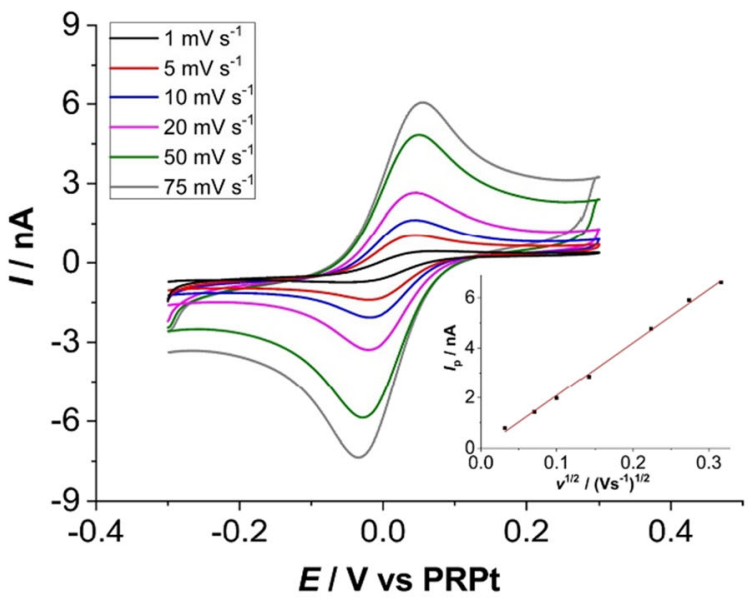

c)

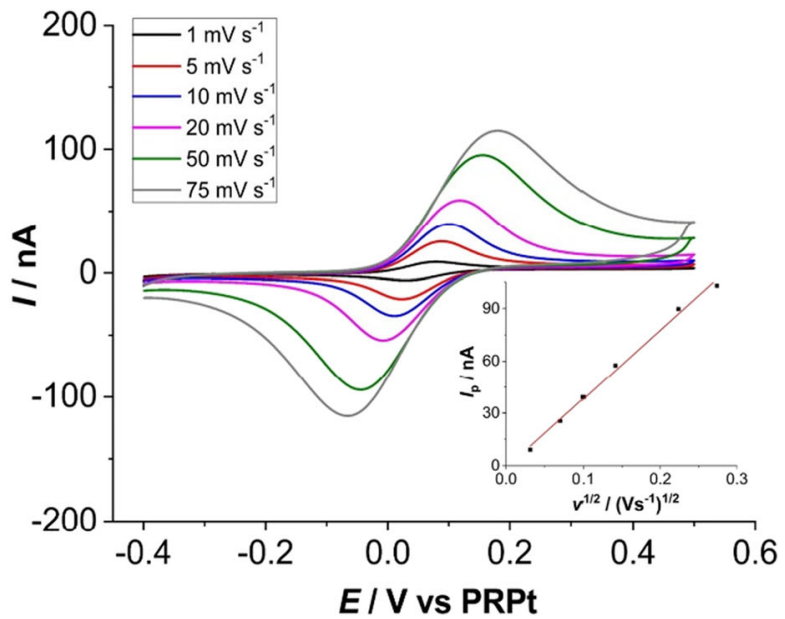

Fig. 4 a Typical approach curve obtained with the hydrogel-filled micropipette towards a conducting substrate. $\mathbf{b}$ and $\mathbf{c} \mathrm{CVs}$ obtained at different scan rates, as indicated, with the micropipette filled with hydrogel and aqueous solution, respectively, containing $1 \mathrm{mM}\left[\mathrm{Fe}(\mathrm{CN})_{6}\right]^{4-}$ and $0.1 \mathrm{M}$ $\mathrm{KCl}$. Insets: $I_{\mathrm{p}}$ vs. $v^{1 / 2}$ plots

the occurrence of a more complex mass transport condition cannot be excluded [42]. These effects could be related to the fact that with the aqueous-filled microcapillary, the electrolyte spread around the micropipette orifice leading to an increase of the active surface area on the substrate. 
The surface area, and consequently, the diameters of the meniscuses contacting the substrate were estimated using Eq. (2), the slopes of the $I_{\mathrm{p}}$ vs. $v^{1 / 2}$ plots, and the diffusion coefficients shown in Table 2 for $\left[\mathrm{Fe}(\mathrm{CN})_{6}\right]^{4-}$. The contact radii thus found were $33( \pm 2) \mu \mathrm{m}$ and $139( \pm 5) \mu \mathrm{m}$, for the pipette filled with the hydrogel and aqueous solution, respectively. These results clearly indicated that, while the gelled meniscus remained essentially confined to the micropipette end, the aqueous meniscus spread onto the substrate. In fact, it is known that to ensure the confinement of protruding aqueous meniscuses, the outer walls of the micropipettes need to be silanized (typically, with dimethydichorosilane [27, 28]. As stated in experimental, no such kind of treatment was applied to the micropipettes used here.

The stability of the gelled meniscus with time was then investigated, and Fig. 5 shows, as an example, two CVs recorded at $50 \mathrm{mV} \mathrm{s}^{-1}$ soon after the meniscus had landed on the substrate (black line), and after, it was held in place for about $1 \mathrm{~h}$ (red line). As is evident the two CVs almost overlap, indicating a good stability of the meniscus with time. This result supports the observation that the hydrogel-filled micropipette prevents the spreading and leakage of electrolyte.

Measurements as those discussed above were also performed by using micropipettes characterized by smaller orifices, i.e., below $30-\mu \mathrm{m}$ radius, containing $\left[\mathrm{Fe}(\mathrm{CN})_{6}\right]^{4-}$ as redox probe. The results obtained were similar to those described above (that is, peak shaped CVs), provided that the orifices, and the corresponding contact meniscuses, were larger than about $5-\mu \mathrm{m}$ radius. With smaller micropipettes and contact radii (i.e., $2 \mu \mathrm{m}$ ), mixed planar-radial or radial diffusion prevailed, and sigmoidal CV responses (depending on the scan rate), similar to those recorded in the bulk media with the 12.5- $\mu \mathrm{m}$ radius Pt disk, could be recorded. As an example, Fig. 6 shows two $\mathrm{CVs}$ recoded at $5 \mathrm{mV} \mathrm{s}^{-1}$ with the same

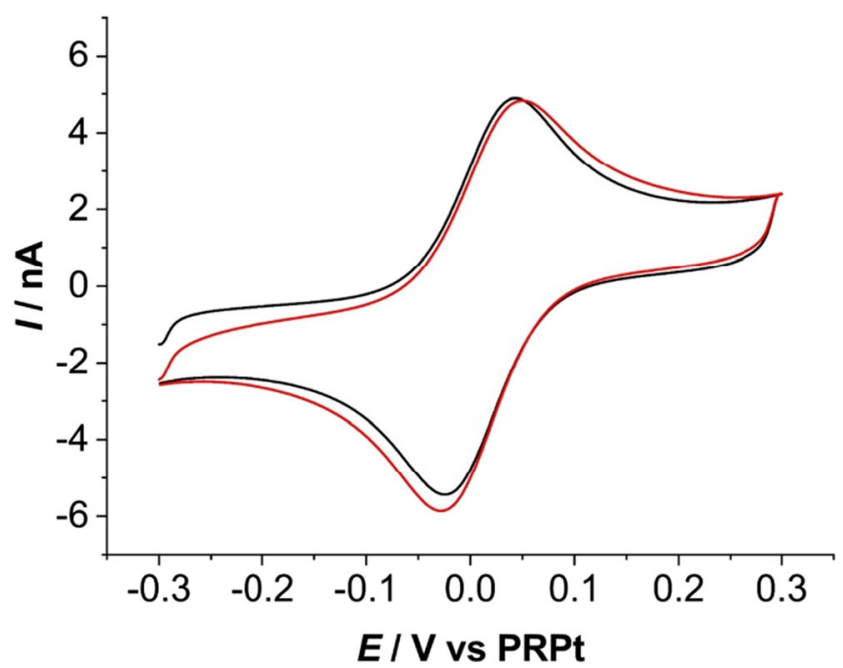

Fig. $5 \mathrm{CVs}$ recorded at $50 \mathrm{mV} \mathrm{s}^{-1}$ with the hydrogel-filled micropipette containing $1 \mathrm{mM}\left[\mathrm{Fe}(\mathrm{CN})_{6}\right]^{4-}$ and $0.1 \mathrm{M} \mathrm{KCl}$, just after it had landed on to the substrate (black line), and after $1 \mathrm{~h}$, it was held in place (red line)

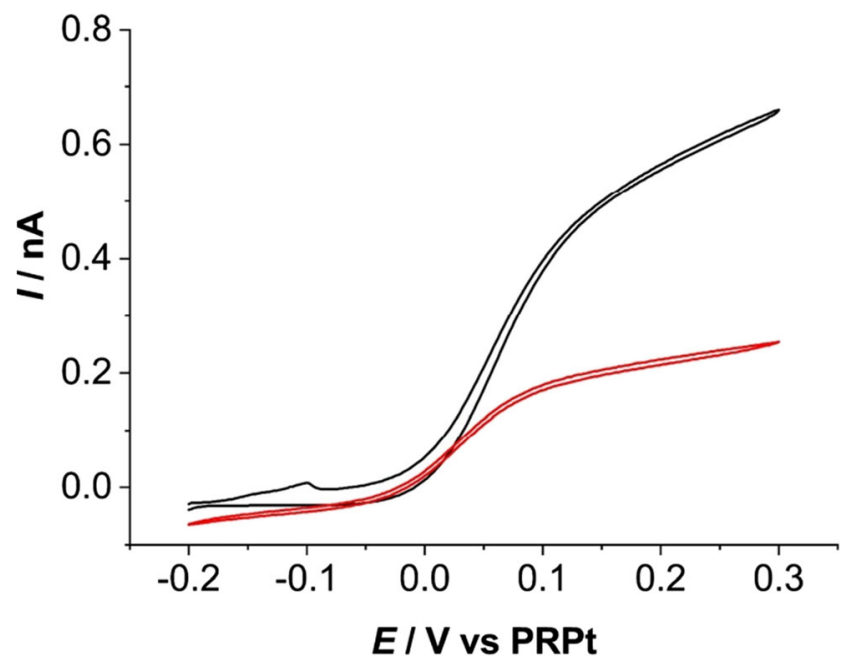

Fig. $6 \mathrm{CVs}$ recorded at $5 \mathrm{mV} \mathrm{s}^{-1}$ with the micropipette filled with hydrogel (red line) and aqueous solution (black line) containing $1 \mathrm{mM}$ $\left[\mathrm{Fe}(\mathrm{CN})_{6}\right]^{4-}$ and $0.1 \mathrm{M} \mathrm{KCl}$

micropipette (1.5- $\mu \mathrm{m}$ radius) filled with the hydrogel (red line) and aqueous (black line) solutions, respectively. This behavior is congruent with literature reports, where pipettes having just a few micrometers or submicrometers dimensions were investigated [40]. It must be considered that also in these cases the CVs recorded with the aqueous-filled micropipette provided larger currents than expected (i.e., about twice), conceivably due to spreading and leakage of solution on the substrate surface.

\section{Microelectrode and micro capillary voltammetry of $\mathrm{Ag}^{+}$ions in agarose hydrogel and water media}

The voltammetry behavior of $\mathrm{Ag}^{+}$ions in the agarose hydrogel and, for comparison, in the corresponding aqueous medium, was investigated both in the bulk media and in the capillary contact mode. The measurements were performed in the media contained $1 \mathrm{mM} \mathrm{AgNO}_{3}$, and to avoid the formation of sparingly soluble $\mathrm{AgCl}, 0.1 \mathrm{M} \mathrm{KNO}_{3}$ was used as the supporting electrolyte.

The electrode process involved is:

$\mathrm{Ag}^{+}+\mathrm{e}^{-} \rightleftarrows \mathrm{Ag}^{0}$

Figure 7 contrasts $\mathrm{CVs}$ recorded at $5 \mathrm{mV} \mathrm{s}^{-1}$ in bulk hydrogel and water solution with the microelectrode. In both cases, the CVs display the characteristic signatures of metal electrodeposition at the surface of microelectrodes, involving nucleation and growth of a new metallic phase and dissolution of the metal deposited from the electrode surface [30, 43, 44]. In fact, waves achieving quasi-steady-state current values are obtained in the cathodic sweep, while characteristic nucleation loops, followed by stripping peaks, are evident on reversal of the sweep. However, a nucleation overpotential of about 50 $\mathrm{mV}$, a shift of the stripping peak towards more positive 


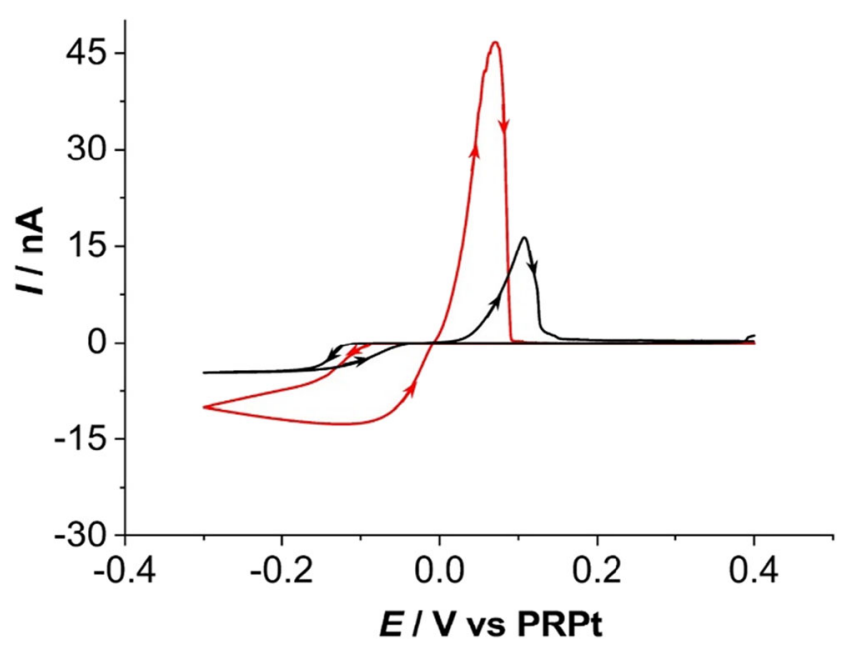

Fig. $7 \mathrm{CVs}$ recorded at a $\mathrm{Pt}$ microdisk $12.5-\mu \mathrm{m}$ radius in solution containing $1 \mathrm{mM} \mathrm{AgNO}+0.1 \mathrm{M} \mathrm{KNO}_{3}$ in (black line) hydrogel and (red line) aqueous solution. Scan rate $5 \mathrm{mV} \mathrm{s}^{-1}$

potentials (i.e., of $35 \mathrm{mV}$ ), and lower current intensities of waves/peaks (depending on the sweep direction) were found in the hydrogel with respect to the aqueous solution. These differences can be accounted for considering, from one side, the effect of agarose on the nucleation/dissolution process of the $\mathrm{Ag}^{+} / \mathrm{Ag}^{\circ}$ system on/from the surface of a platinum electrode [45]; from the other side to the different diffusion coefficient of $\mathrm{Ag}^{+}\left(D_{\mathrm{Ag}+}\right)$ that, conceivably, applies in the two media. From the current plateaus recorded in the forward scan of the CVs and Eq. (1), $D_{\mathrm{Ag}+}$ values were evaluated and included in Table 1. $D_{\mathrm{Ag}+}$ found here in the aqueous solution compares well with literature reports $[30,46-48]$. No datum was available for $\mathrm{Ag}^{+}$ions in $2 \%$ (w/v) agarose hydrogel. However, the $D_{\text {gel }} / D_{\text {aq }}$ ratio of 0.75 (Table 1) is within those found for the above investigated soluble species, indicating that no specific interaction exists between $\mathrm{Ag}^{+}$ions and the agarose hydrogel structure.

A further distinctive difference, between the features of the CVs obtained in the two media, was the charge involved in the anodic peak $\left(Q_{\mathrm{an}}\right)$ with respect to that involved in the cathodic going scan $\left(Q_{\text {ca }}\right)$. In fact, while in the water phase the $Q_{\text {an }} / Q_{\text {ca }}$ ratio was $0.94 \pm 0.04$ (from three replicates), in the hydrogel, it was lower (from about 0.3 to 0.4 times). Since the total amount of charge under the waves/peaks is related to the amount of silver plated or dissolved, respectively, the above results suggest that in the hydrogel, apparently, only a fraction of the metallic silver deposited is stripped from the electrode surface. We actually believe that part of metallic silver deposited (probably as nanoparticles [49] detaches from the electrode surface and diffuse in the hydrogel. This can also be related to the growth mode of silver electrodeposits, which, in agarose-containing solutions, result in a less stable open branched pattern that behaves as a surface and mass fractal [45].
Capillary contact measurements were performed with a $2-\mu \mathrm{m}$ diameter pipette filled with either the hydrogel or the corresponding aqueous solution, containing $1 \mathrm{mM} \mathrm{AgNO}_{3}$, and typical CVs recorded at $50 \mathrm{mV} \mathrm{s}^{-1}$ are shown in Fig. 8a. Because of the smaller size of the pipette orifice, the forward cathodic current is almost independent on scan rate over the range $5 \div 100 \mathrm{mV} \mathrm{s}^{-1}$ (Fig. 8b), whereas the anodic stripping peak, being a surface process, increases with the scan rate [44]. From the quasi-steady-state current recorded in the hydrogel at $5 \mathrm{mV} \mathrm{s}^{-1}$ and Eq. (1), using the $D_{\mathrm{Ag}+}$ shown in Table 1 , contact meniscuses of $1.1-\mu \mathrm{m}$ and $1.5-\mu \mathrm{m}$ radii were evaluated with the micropipette filled with the hydrogel and aqueous solution, respectively. Again, also in this case, the aqueous meniscus resulted larger than that of the hydrogel, likely due to the same phenomenon described above for the soluble redox probe.

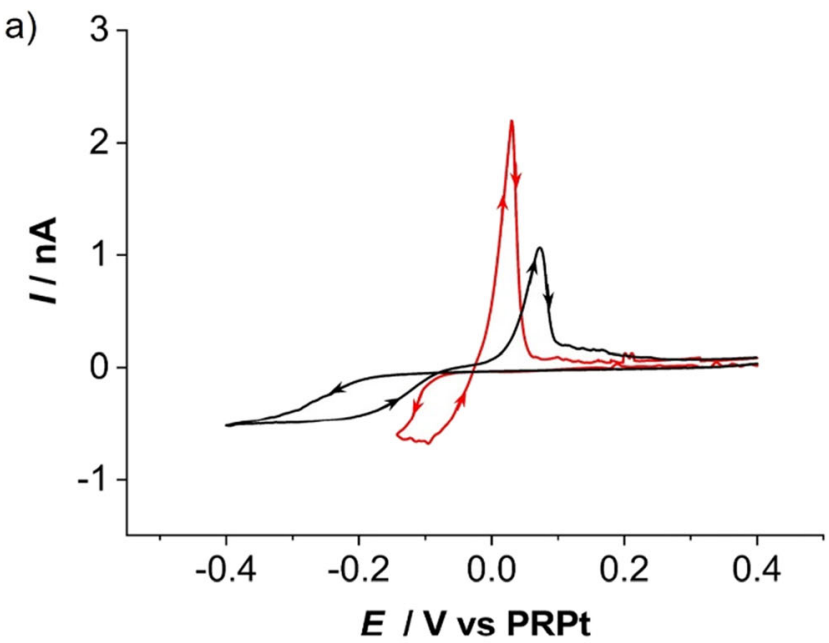

b)

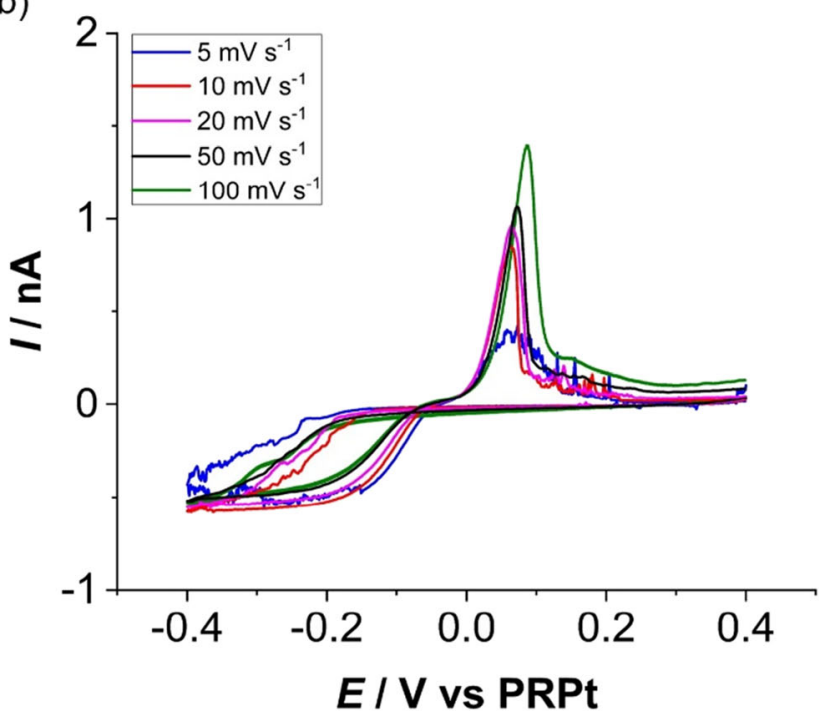

Fig. 8 a CVs recorded at $5 \mathrm{mV} \mathrm{s}^{-1}$ with a hydrogel- (black line) and aqueous-filled (red line) micropipette (1- $\mathrm{mm}$ radius) containing $1 \mathrm{mM}$ $\mathrm{AgNO}_{3}+0.1 \mathrm{M} \mathrm{KNO}_{3}$. b CVs recorded at different scan rates, as indicated, with the hydrogel-filled micropipette having the same composition as in (a) 
Evaluation of the charge involved in the cathodic and anodic branches revealed a similar behavior as that observed with the Pt microelectrode in the bulk media. That is, $Q_{\mathrm{an}} /$ $Q_{\text {ca }}$ was of about 0.5 and 0.9 for the micropipette filled with the hydrogel and aqueous solution, respectively, again in accordance with the observations made above in the bulk media.

\section{Hydrogel microcapillary measurements on paper- based materials}

Proof-of-concept hydrogel-capillary measurements were performed to distinguish the presence of metallic silver deposited on a graphite-on-paper-based material, realized through simple pencil strokes, as described in the experimental section. The graphite layer allowed making the electrical contact of the whole sample with the external circuit. In these measurements, a micropipette (orifice $5-\mu \mathrm{m}$ radius) filled with the agarose hydrogel, containing only $0.1 \mathrm{M} \mathrm{KNO}_{3}$, was employed. Initially, the micropipette was brought above the graphite layer to establish the electrical contact with the substrate biased at $+0.4 \mathrm{~V}$ vs. PRPt. Afterward, repetitive retraction-approaching processes were performed to detach the probe from a given measuring point, move it laterally to the next point and approach the substrate again. In this way, a line scan at the boundary between the Ag-free and Ag-coated graphite layer was performed. Each time the micropipette had landed on the substrate, continuously biased at $+0.4 \mathrm{~V}$, the current was monitored for $5 \mathrm{~s}$, and the value corresponding at $5 \mathrm{~s}\left(I_{5 \mathrm{~s}}\right)$ was plotted as a function of the lateral distance $(d)$, as shown in Fig. 9. In this way, negligible currents, essentially due to the background, were obtained when the micropipette

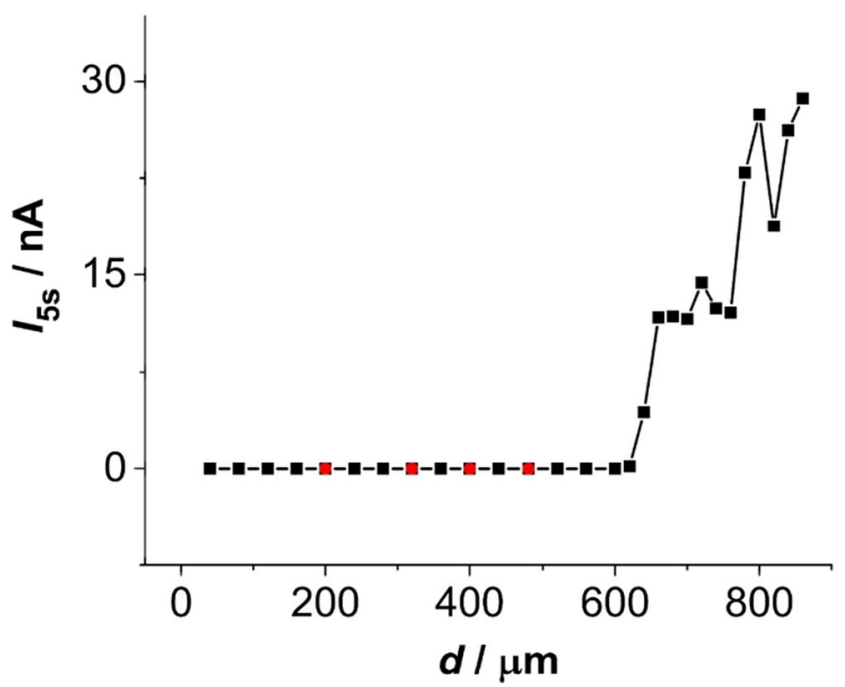

Fig. 9 Current-distance plot obtained above a graphite-on-paper-based substrate, coated with silver deposits. The substrate was biased at $0.4 \mathrm{~V}$ vs. PRPt. The plot was recorded using a micropipette filled with the agarose hydrogel, containing $0.1 \mathrm{M} \mathrm{KNO}_{3}$. Black square symbols refer the forward lateral scan, while red symbols refer to control measurements performed by moving back the micropipette on the Ag-free graphite layer landed on the Ag-free graphite zone, whereas much larger currents were recorded above the Ag-coated graphite layer. In fact, at $+0.4 \mathrm{~V}$, the oxidation process of metallic silver could occur (see Figs. 7 and 8), and the current was enhanced to an extent that depended, conceivably, on the amount of metallic silver coating the sample. To confirm this view, control experiments were performed by moving back the micropipette above the Ag-free graphite zone, where again negligible currents were recorded (see red symbols in Fig. 9). Therefore, the results shown in Fig. 9 reflect the distribution of metallic silver is on the pencil-graphite layer as well as its relative amount.

\section{Conclusions}

In this work, for the first time, we have reported on the use of micropipettes filled with a conducting hydrogel, made of $2 \%$ $(\mathrm{w} / \mathrm{v})$ agarose in water solutions, to perform local solid contact electrochemical measurements on solid substrates. In particular, we have shown that micropipettes having orifices of radii over the range 1-30 $\mu \mathrm{m}$, filled with the hydrogel containing the electroactive species $\left[\mathrm{Fe}(\mathrm{CN})_{6}\right]^{4-}$ or $\mathrm{Ag}^{+}$ions, provide electrochemical responses, which are in accordance with theory developed for microcapillary voltammetry. The microsystems employed here can be used to probe small areas of solid surfaces containing different active materials and to produce micrometers and submicrometers metallic structures by electrodeposition. These can be associated to a specific advantage offered by the gelled meniscus produced at the end of the micropipettes. In fact, they could overcome the limitations of the corresponding aqueous systems, with which the spreading of the electrolyte droplet on the sample surface is difficult to be controlled. Finally, the use of gelled media within the pipette opens new roads for the characterization, from an electrochemical point of view, of microareas on surfaces, which suffer from direct contact with liquid electrolytes.

\section{References}

1. Mohanty S, Mishra S, Jena P, Jacob B, Sarkar B, Sonawane A (2012) Nanomedicine: Nanotechnology, Biology, and Medicine 8:916-924.

2. Incoronato AL, Buonocore GG, Conte A, Lavorgna M, Del Nobile MA (2010) J Food Prot 73(12):2256-2262

3. Rhim JW, Wang LF (2013) Hong SI. Food Hydrocoll 33(2):327335

4. Wu J, Black JJ, Aldous L (2017) Electrochim Acta 225:482-492

5. Cao L, Yang M, Wu D, Lyu F, Sun Z, Zhong X, Pan H, Liuc H, Lu Z (2017) Chem Commun 53(10):1615-1618

6. Kaneko M, Nomura T, Sasaki C (2003) Macromolecular rapid communications, 24:444-446, 7. 
7. Dhanjai SA, Kalambate PK, Mugo SM, Kamau P, Chen J, Jain R (2019) Trends Anal Chem 118:488-501

8. Belmont-Hébert C, Tercier ML, Buffle J, Fiaccabrino GC, De Rooij NF, Koudelka-Hep M (1998) Anal Chem 70(14):2949-2956

9. Lee MH, Kim YT (1999) Electrochemical and solid-state. Letters 2(2):72-74

10. Cano E, Crespo A, Lafuente D, Barat BR (2014) Electrochem Commun 41:16-19

11. Barat BR, Cano E (2015) Electrochim Acta 182:751-762

12. Barat BR, Cano E, Letardi P (2018) Sensors Actuators B 261:572580

13. Di Turo F, Matricardi P, Di Meo C, Mazzei F, Favero G, Zane D (2019) J Cult Herit 37:113-120

14. Di Turo F, De Vito C, Coletti F, Mazzei F, Antiochia R, Favero G (2017) Microchem J 134:154-163

15. Liu L, Etienne M, Walcarius A (2018) Anal Chem 90(15):88898895

16. Dang N, Etienne M, Walcarius A, Liu L (2018) Electrochem Commun 97:64-67

17. Kang H, Hwang S, Kwak J (2015) Nanoscale 7(3):994-1001

18. Ebejer N, Guell AG, Lai SCS, McKelvey K, Snowden ME, Unwin PR (2013) Annu Rev Anal Chem 6(1):329-351

19. Rodolfa KT, Bruckbauer A, Zhou D, Korchev YE, Klenerman D (2005) Angw Chem Int Ed 44(42):6854-6859

20. Suter T, Bohni H (1997) Electrochim Acta 42:3275-3280

21. Bohni H, Suter T, Assi F (2000) Surf Coat Technol 130(1):80-86

22. Lohrengel MM, Rosenkranz C, Kluppel I, Moehring A, Bettermann H, Van den Bossche B, Deconinck J (2004) Electrochim Acta 49:2863-2870

23. Andreatta F, Lohrengel MM, Terryn H, De Wit JHW (2003) Electrochim Acta 48:3239-3247

24. Vignal V, Krawiec H, Heintz O, Oltra R (2007) Electrochim Acta 52:4994-5001

25. Souto RM, Izquierdo J, Santana J, Gonzalez S (2013) Eur J Sci Technol 9:71-89

26. Ho HLT, Dryfe RAW (2009) Langmuir 25(21):12757-12765

27. Shao Y, Mirkin MV (1998) Anal Chem 70(15):3155-3161

28. Macpherson JV, Unwin PR (1999) Anal Chem 71(20):4642-4648

29. Dossi N, Toniolo R, Pizzariello A, Impellizzieri F, Piccin EG, Bontempelli G (2013) Electrophoresis 34:2085-2091
30. Battistel D, Pecchielan G, Daniele S (2014) Chem.ElectroChem 1(1):140-146

31. Saito Y (1968) Rev Polarogr 15(6):177-187

32. Lindsey G, Abercrombie S, Denuault G, Daniele S, De Faveri E (2007) Anal Chem 79(7):2952-2956

33. Littauer EL, Shreir LL (1966) Electrochim Acta 11(5):527-536

34. Horányi G, Vértes G (1973) J Electroanal Chem Interfacial Electrochem 45(2):295-299

35. Daniele S, Battistel D, Bergamin S, Bragato C (2010) Electroanalysis 22(13):1511-1518

36. Bard AJ, Faulkner LR (2001) Electrochemical methods: fundamentals and applications. John Wiley \& Sons

37. Zhang M, Xiong L, Compton RG (2013) Anal. Methods 5:34733481

38. Bragato C, Daniele S, Baldo MA, Denuault G (2002) Ann Chim 92(3):153-161

39. Csoka B, Nagy G (2004) J Biochem Biophys Methods 61:57-56

40. Williams CG, Edwards MA, Colley AL, Macpherson JV, Unwin PR (2009) Anal Chem 81(7):2486-2495

41. Nicholson RS (1965) Anal Chem 37(6):667-671

42. Aoki KJ, Chen J, Liu Y, Jia B (2020) J Electroanal Chem 856: 11369

43. Scharifker B, Hills GJ (1981) J Electroanal Chem 130:81-97

44. Baldo MA, Bragato C, Mazzocchin GA, Daniele S (1998) Electrochim Acta 43:3413-3422

45. Pasquale MA, Marchiano SL, Bolzán AE, Arvia AJ (2003) J Appl Electrochem 33(5):431-441

46. von Stackelberg M, Pilgram M, Toome V (1953) Z Elektrochem $57: 342-350$

47. Xiang C, Xie Q, Hu J, Yao S (2005) J Electroanal Chem 584(2): 201-209

48. Pecchielan G, Baldo MA, Fabris S, Daniele S (2019) J Electroanal Chem 847:113166

49. Hasse U, Scholz F (2006) J Solid State Electrochem 10(6):380-382

Publisher's note Springer Nature remains neutral with regard to jurisdictional claims in published maps and institutional affiliations. 